\title{
LA GASTRONOMÍA COMO ELEMENTO INMATERIAL EN LA DECLARACIÓN DE BIENES DE INTERÉS CULTURAL DE LA COMUNITAT VALENCIANA (ESPAÑA) Y SU INFLUENCIA EN EL DESTINO TURÍSTICO
}

\author{
GASTRONOMY AS AN INTANGIBLE ELEMENT IN THE DECLARATION \\ OF ASSETS OF CULTURAL INTEREST OF THE VALENCIAN \\ COMMUNITY (SPAIN) AND ITS INFLUENCE ON THE TOURIST \\ DESTINATION
}

Francisca Ramón Fernández

Universitat Politècnica de València, España

\section{RESUMEN}

En el presente trabajo se plantea como objetivo analizar la importancia de la gastronomía, mencionada en la Declaración de los Bienes de Interés Cultural de la Comunitat Valenciana, España. Se hace referencia a esta manifestación cultural que tiene un valor de identidad territorial y cultural y que se convierte en un elemento relevante para elegir un destino turístico. El turista gastronómico, al igual que el turista de ciudad, muestra interés por la degustación de platos típicos de un lugar. El turismo gastronómico es una actividad que representa incremento de los recursos en la zona turística, y en consecuencia, aporta en la preservación de la identidad cultural.

Palabras clave: gastronomía, bien de interés cultural, patrimonio inmaterial, destino turístico, Comunitat Valenciana.

\section{ABSTRACT}

In this paper we analyze the importance of gastronomy, mentioned in the Declaration of Assets of Cultural Interest of the Valencian Community, Spain; which refers to this cultural manifestation that has a territorial and cultural identity value, and that becomes a relevant element to choose a tourist destination. The gastronomic tourist, like the city tourist, shows interest in tasting typical dishes of a destination. Gastronomic tourism is an activity that represents an increase in resources in the tourist area, and consequently, contributes to the preservation of cultural identity.

Keywords: gastronomy, assets of cultural interest, intangible heritage, tourist destination, Valencian Community.

Este es un artículo Open Access bajo la licencia Creative Commons AtribuciónNoComercial-Compartirlgual 4.0

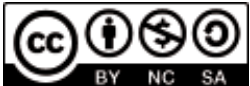




\section{La gastronomía como bien inmaterial y su protección en el patrimonio cultural}

El término patrimonio se suele relacionar con un bien inmueble, principalmente con un monumento. Sin embargo, la noción de patrimonio va más allá de los monumentos; incluye lo que se denomina bienes inmateriales, o bienes intangibles. Por tanto, la idea restrictiva de patrimonio como compuesto solo por bienes materiales (muebles e inmuebles), entre los que se incluyen monumentos, jardines, documentos, se amplía con las manifestaciones culturales y las costumbres, como la lengua, la música y, cómo no, la gastronomía (Martín, 2008; Ramón, 2012a, 2012b).

\section{¿Qué es la gastronomía?}

El concepto de gastronomía es muy amplio y se relaciona con los temas referidos a la cocina tradicional, la idiosincrasia, los alimentos típicos de una determinada región o zona geográfica; que en el ámbito jurídico, incluso, se protegen mediante marcas de calidad, denominaciones de origen o indicaciones geográficas protegidas.

La gastronomía tiene varias acepciones:

a. El arte de preparar una buena comida: relacionado con el buen comer, y la preparación como técnica para obtener un plato adecuado.

b. Afición al buen comer: donde se prima la persona, como el gastrónomo; teniendo en cuenta el placer y disfrute que proporciona la comida.

c. Conjunto de platos y usos culinarios propios de un determinado lugar; considerando la cocina tradicional y típica de un lugar e identidad de las costumbres culinarias de la zona (Real Academia Española, 2020).

La gastronomía va más allá de un acto necesario para la vida. El comer y la comida abarcan toda una cultura y refleja la identidad de un lugar (Alonso, 2018; Fusté, 2015; Torres et al., 2017, 2018). También, forma parte de la educación del ser humano, por ejemplo, comer alimentos sanos, naturales y dieta equilibrada (Reyes et al., 2017).

Además, la gastronomía está incorporada en el denominado turismo cultural o turismo gastronómico, donde no solo se reconoce el plato típico de un lugar, también se refleja el significado que representa para dicho lugar los alimentos que componen la receta. Se le concibe como el arte y la ciencia del buen comer y beber, concepto que se extiende a la tradición, cultura y civilización. Se establece una relación entre comida, cultura, arte y ciencia para preparar y servir comida rica, delicada y apetitosa (Bahls et al., 2019).

Por lo expuesto, la gastronomía es cultura y es evidente que contribuye para valorar esta cultura al representar la identidad de un territorio. La asociación de un producto gastronómico con un lugar puede ser tan intensa que llega a anular a cualquier otro elemento que forme parte del patrimonio. La preservación del patrimonio se enlaza con la gastronomía, tanto así, que si desaparece la gastronomía, desaparece gran parte del patrimonio. 
Por otra parte, la segmentación del mercado favorece la generación de nuevos productos turísticos relacionados con la gastronomía, tales como rutas turísticas gastronómicas, catas de productos típicos y el auge de un mercado de productos de proximidad. Esto, supone un incremento económico considerable, una generación de empleo y de supervivencia para las localidades mediante el impulso que supone dinamizar el territorio por la gastronomía al crear nuevos productos, espacios y experiencias (Maldonado-Erazo et al., 2019; Martín, 2008).

Es importante señalar, que la gastronomía se relaciona, no solo al turismo cultural, sino también al turismo de experiencias o de sensaciones; se incluye en lo que se denomina turismo vivencial, que es un instrumento de desarrollo rural (Monllor-Rico y Soy-Massoni, 2018). Este tipo de turismo está dirigido a personas interesadas en conocer otros productos, diferentes del habitual turismo de sol y playa; que se centra más en aspectos de la cocina tradicional o métodos de cocción de alimentos, e incluso, alimentos desconocidos pero habituales en una zona concreta de la geografía. En este sentido, el turista al elegir un destino para vacacionar no busca un lugar, sino una experiencia, una vivencia diferente a la que tiene cotidianamente. Es decir, son los aspectos sensoriales los que hacen que la experiencia sea única.

El turista se ve atraído por la degustación, por el gusto, por el paladar; con todas las connotaciones que tiene la comida como experiencia única busca probar la gastronomía local o degustar sabores diferentes a los acostumbrados. También, se ve atraído por la denominada cocina tradicional, que puede evocarle recuerdos familiares y de su infancia. El rescate de recetas tradicionales y antiguas, y la creación de elaboraciones típicas es una forma de pervivencia de la cultura a través de las generaciones, en definitiva, de sostenibilidad (Ramón, 2018).

Dentro de los objetivos de desarrollo sostenible se toma el referido a la producción y consumo responsable para establecer la relación entre gastronomía, alimentación y alimentos; industria que mueve gran parte de la economía mundial. La doctrina aborda también la «gastronomía creativa» como innovación, mediante el uso de ingredientes presentados de forma novedosa (Maldonado et al., 2019). Se busca también, como atractivo para el turista, la «memoria culinaria», recuerdos de productos gastronómicos que le evocan una época, recuerdo o situación vivida, un tipo de déjà vu. Un símil con En busca del tiempo perdido, de Marcel Proust, y la evocación que provoca una magdalena, en Por el camino de Swann, del mismo autor.

\section{La gastronomía y su protección en el ámbito del patrimonio cultural}

El instrumento de ratificación de la Convención para la Salvaguardia del Patrimonio Cultural Inmaterial, hecho en París el 3 de noviembre de 2003 (BOE n. ${ }^{\circ}$ 31, de 5 de febrero de 2007), considera como patrimonio cultural inmaterial:

Los usos, representaciones, expresiones, conocimientos y técnicas -junto con los instrumentos, objetos, artefactos y espacios culturales que les son inherentes- que las comunidades, los grupos y en algunos casos los individuos reconozcan como parte integrante de su patrimonio cultural. Este patrimonio cultural inmaterial, que se transmite de generación en generación, es recreado constantemente por las comunidades y grupos en función de su entorno, su interacción con la 
naturaleza y su historia, infundiéndoles un sentimiento de identidad y continuidad y contribuyendo así a promover el respeto de la diversidad cultural y la creatividad humana. A los efectos de la presente Convención, se tendrá en cuenta únicamente el patrimonio cultural inmaterial que sea compatible con los instrumentos internacionales de derechos humanos existentes y con los imperativos de respeto mutuo entre comunidades, grupos e individuos y de desarrollo sostenible.

El patrimonio, como indica la Convención, se manifiesta en los ámbitos siguientes: tradiciones y expresiones orales, artes del espectáculo; usos sociales, rituales y actos festivos; conocimientos y usos relacionados con la naturaleza y el universo; así como, técnicas artesanales tradicionales.

La Ley 10/2015, de 26 de mayo, para la Salvaguardia del Patrimonio Cultural Inmaterial (BOE n. ${ }^{\circ}$ 126, de 27 de mayo de 2015), en su art. 2, incluye dentro del patrimonio cultural inmaterial la gastronomía, las elaboraciones culinarias y la alimentación (Ramón, 2014, 2016).

En la Ley 10/2015, se hace referencia al Plan Nacional de Salvaguardia del Patrimonio Cultural Inmaterial (2015), que menciona determinadas características de este tipo de patrimonio, como es formar parte de su identidad, ser compartido, la transmisión a otras generaciones, su preservación y su relación con la cultura, así como sus connotaciones sensoriales y experienciales. Incluye, como uno de los ámbitos en los que se manifiesta el patrimonio cultural inmaterial, las formas de alimentación, conocimientos culinarios y dietas; las formas de conservación, condimentación y elaboración de alimentos, según el ciclo anual; los platos y su consumo en el ciclo diario, las preferencias y tabúes en la nutrición, los espacios, motivos y ritos de comensalismo.

Este Plan Nacional de Salvaguardia del Patrimonio Cultural Inmaterial es un instrumento de gestión y cooperación entre la administración estatal, autonómica y local, y demás entidades públicas o privadas, que tiene entre sus funciones, facilitar información y habilitación para permitir interrelacionar los distintos agentes y adoptar criterios y metodologías para el patrimonio cultural inmaterial, además de alertar de riesgos y amenazas.

En el ámbito legislativo foral y autonómico, los instrumentos legales articulados que rigen el patrimonio cultural en relación con la gastronomía se aprecian en la Tabla 1. 
Tabla 1

Instrumentos legales articulados que rigen el patrimonio cultural en relación con la gastronomía. Mostrando su evolución

\begin{tabular}{|c|c|c|c|c|c|}
\hline $\begin{array}{l}\text { Comunidad } \\
\text { Autónoma }\end{array}$ & $\begin{array}{l}\text { Legislación } \\
\text { aplicable }\end{array}$ & Articulado & Protección & Bien & Medidas \\
\hline Illes Balears & $\begin{array}{l}\text { Ley 18/2019, de } 8 \text { de } \\
\text { abril, de salvaguardia } \\
\text { del patrimonio cultural } \\
\text { inmaterial (BOE n. }^{\circ} 109 \text {, } \\
\text { de } 7 \text { de mayo de } 2019 \text { ). }\end{array}$ & Artículo 3 & $\begin{array}{l}\text { El patrimonio cultural } \\
\text { inmaterial (PCI) se } \\
\text { manifiesta en la salud, } \\
\text { alimentación, } \\
\text { gastronomía y } \\
\text { elaboraciones } \\
\text { culinarias. }\end{array}$ & $\begin{array}{l}\text { Bien cultural } \\
\text { inmaterial }\end{array}$ & $\begin{array}{l}\text { Garantizar la transmisión a } \\
\text { generaciones futuras. } \\
\text { Participación ciudadana. } \\
\text { Interculturalidad. } \\
\text { Desarrollo sostenible. } \\
\text { Documentación, } \\
\text { identificación, investigación, } \\
\text { preservación, } \\
\text { reconocimiento, difusión y } \\
\text { revitalización. }\end{array}$ \\
\hline
\end{tabular}

\begin{tabular}{|c|c|c|c|c|c|}
\hline $\begin{array}{l}\text { Comunitat } \\
\text { Valenciana }\end{array}$ & $\begin{array}{l}\text { Ley 4/1998 de } 11 \text { de } \\
\text { junio, del Patrimonio } \\
\text { Cultural Valenciano } \\
\text { (BOE n. }{ }^{\circ} 174 \text {, de } 22 \text { de } \\
\text { julio de } 1998 \text { ), } \\
\text { modificada por Ley } 7 / \\
2004 \text {, de } 19 \text { de octubre } \\
\text { (BOE n. }{ }^{\circ} 279 \text {, de } 19 \text { de } \\
\text { noviembre de } 2004 \text { ), } \\
\text { Ley 5/2007, de } 9 \text { de } \\
\text { febrero (BOE n. }{ }^{\circ} 71 \text {, de } \\
23 \text { de marzo de } 2007 \text { ), y } \\
\text { por Ley } 9 / 2017, \text { de } 7 \text { de } \\
\text { abril (BOE n. }{ }^{\circ} 112, \text { de } \\
11 \text { de mayo de } 2017 \text { ). }\end{array}$ & Artículo 1 & $\begin{array}{l}\text { El patrimonio inmaterial } \\
(\mathrm{PCl}) \text { incluye «las } \\
\text { expresiones de las } \\
\text { tradiciones del pueblo } \\
\text { valenciano en sus } \\
\text { manifestaciones } \\
\text { musicales, artísticas, } \\
\text { deportivas, religiosas, } \\
\text { gastronómicas o de } \\
\text { ocio, y en especial } \\
\text { aquellas que han sido } \\
\text { objeto de transmisión } \\
\text { oral, las que mantienen } \\
\text { y potencian el uso del } \\
\text { valenciano». }\end{array}$ & $\begin{array}{l}\text { Bien de Interés } \\
\text { Cultural (BIC) }\end{array}$ & $\begin{array}{l}\text { Incluirá las medidas de } \\
\text { protección y fomento de la } \\
\text { manifestación cultural } \\
\text { objeto de la declaración } \\
\text { que mejor garanticen su } \\
\text { conservación. En cualquier } \\
\text { caso, se ordenará el } \\
\text { estudio y la documentación } \\
\text { con criterios científicos de } \\
\text { la actividad o conocimiento } \\
\text { de que se trate, } \\
\text { incorporando los } \\
\text { testimonios disponibles de } \\
\text { estos a soportes materiales } \\
\text { que garanticen su } \\
\text { pervivencia. }\end{array}$ \\
\hline $\begin{array}{l}\text { Comunitat } \\
\text { Valenciana }\end{array}$ & $\begin{array}{l}\text { Decreto 62/2011, de } 20 \\
\text { de mayo, del Consell, } \\
\text { por el que se regula el } \\
\text { procedimiento de } \\
\text { declaración y el } \\
\text { régimen de protección } \\
\text { de los bienes de } \\
\text { relevancia local (DOGV } \\
\text { n. } 6529 \text {, de } 26 \text { de } \\
\text { mayo de } 2011 \text { ). }\end{array}$ & Artículo 55 & $\begin{array}{l}\text { Bienes circunscritos a } \\
\text { un ámbito territorial más } \\
\text { limitado, y que no } \\
\text { reúnen las } \\
\text { características para ser } \\
\text { declarados como bien } \\
\text { de interés cultural, pero } \\
\text { sí como Bienes de } \\
\text { Relevancia Local (BRL). }\end{array}$ & $\begin{array}{l}\text { Bienes de } \\
\text { Relevancia Local } \\
\text { (BRL) }\end{array}$ & $\begin{array}{l}\text { Estos bienes «se incluirán } \\
\text { en el Inventario General del } \\
\text { Patrimonio Cultural } \\
\text { Valenciano, con la } \\
\text { calificación de Bienes } \\
\text { Inmateriales de Relevancia } \\
\text { Local, aquellas creaciones, } \\
\text { conocimientos, prácticas, } \\
\text { técnicas, usos y actividades } \\
\text { más representativas y } \\
\text { valiosas de la cultura y las } \\
\text { formas de vida tradicionales } \\
\text { valencianas. Igualmente se } \\
\text { incluirán los bienes } \\
\text { inmateriales que sean } \\
\text { expresiones de las } \\
\text { tradiciones del pueblo } \\
\text { valenciano en sus } \\
\text { manifestaciones musicales, } \\
\text { artísticas, gastronómicas o } \\
\text { de ocio, y en especial } \\
\text { aquellas que han sido objeto } \\
\text { de transmisión oral y las } \\
\text { que mantienen y potencian } \\
\text { el uso del valenciano». }\end{array}$ \\
\hline
\end{tabular}

Nota Elaboración propia. 


\section{La gastronomía en las declaraciones de bienes de interés cultural y de relevancia local de la Comunitat Valenciana}

Se desarrolla, en este punto, la gastronomía en la declaración de bien de interés cultural y bien de relevancia local en distintas manifestaciones y fiestas de la Comunitat Valenciana; donde ocupa un lugar esencial y está íntimamente relacionada con la fiesta, lo que demuestra su vinculación con un territorio, vale decir, forma parte de la identidad (ver Tabla 2).

Tabla 2

Declaraciones de bienes de interés cultural y bienes de relevancia local y la presencia de la gastronomía

\begin{tabular}{|c|c|c|c|c|c|c|}
\hline Festividad & Lugar & Calendario & Conmemoración & $\begin{array}{l}\text { Cristiana, } \\
\text { pagana } 0 \\
\text { secular }\end{array}$ & $\begin{array}{c}\text { Preparaciones, comidas } 0 \\
\text { bebidas servidas } \\
\text { para la ocasión }\end{array}$ & Protección \\
\hline $\begin{array}{l}\text { Moros y } \\
\text { Cristianos }\end{array}$ & Alcoy & $\begin{array}{l}\text { La proclamación de la } \\
\text { fiesta se realiza con la } \\
\text { Gloria en la mañana } \\
\text { del domingo de } \\
\text { Pascua de } \\
\text { Resurrección. La } \\
\text { trilogía festera toma } \\
\text { como eje el } 23 \text { de } \\
\text { abril, festividad de San } \\
\text { Jorge. }\end{array}$ & San Jorge & Cristiana & $\begin{array}{l}\text { Sopa o Sopar de } \\
\text { l'Olla, que es un } \\
\text { potaje preparado a } \\
\text { partir de la cocción } \\
\text { de alubias, cardos, } \\
\text { costillas de cerdo, } \\
\text { corazón asadura, } \\
\text { morcillas de } \\
\text { cebollas, nabos, } \\
\text { aceite y sal. }\end{array}$ & $\begin{array}{l}\text { Decreto 51/2019, de } \\
29 \text { de marzo, del } \\
\text { Consell, por el que } \\
\text { se declara Bien de } \\
\text { Interés Cultural } \\
\text { Inmaterial con } \\
\text { categoría de Bien } \\
\text { Inmaterial (DOGV } \\
\text { n. } 8526, \text { de } 10 \text { de } \\
\text { abril de } 2019) \text {. }\end{array}$ \\
\hline $\begin{array}{l}\text { Las Festes de } \\
\text { l'Abret d'Altea: } \\
\text { Arbret de Sant } \\
\text { Joan, Arbret de } \\
\text { Sant Roc i } \\
\text { Arbret de Sant } \\
\text { Lluís }\end{array}$ & $\begin{array}{l}\text { Altea: barrio del } \\
\text { Fornet y pueblo } \\
\text { antiguo de Altea, } \\
\text { partidas rurales } \\
\text { de L'Horta y del } \\
\text { Barranquet y } \\
\text { partidas } \\
\text { adyacentes. }\end{array}$ & $\begin{array}{l}\text { Tanto en el Arbret de } \\
\text { Sant Joan como en el } \\
\text { Arbret de Sant Roc y el } \\
\text { Arbret de Sant Lluís, el } \\
\text { traslado del arbret } \\
\text { comienza por la tarde y } \\
\text { la plantà coincide con } \\
\text { la puesta del sol. } \\
\text { Asimismo, las fechas } \\
\text { de celebración son } \\
\text { diferentes, a saber: } \\
\text { Arbret de Sant Joan: } \\
\text { viernes víspera de Sant } \\
\text { Joan (fiestas de Sant } \\
\text { Joan). Arbret de Sant } \\
\text { Roc: sábado víspera } \\
\text { del primer domingo de } \\
\text { agosto (fiestas de Sant } \\
\text { Roc). Arbret de Sant } \\
\text { Lluís: sábado víspera } \\
\text { del último domingo de } \\
\text { agosto (fiestas de Sant } \\
\text { Lluís Bertran). }\end{array}$ & $\begin{array}{l}\text { Arbret de Sant } \\
\text { Joan (fiestas de } \\
\text { Sant Joan); Arbret } \\
\text { de Sant Roc } \\
\text { (fiestas de Sant } \\
\text { Roc) y Arbret de } \\
\text { Sant Lluís: } \\
\text { (fiestas de Sant } \\
\text { Lluís Bertran). }\end{array}$ & $\begin{array}{l}\text { Pagana y } \\
\text { cristiana } \\
\text { Fiestas } \\
\text { arbóreas, } \\
\text { celebración de } \\
\text { la fertilidad } \\
\text { agrícola y de la } \\
\text { juventud }\end{array}$ & $\begin{array}{l}\text { Coca a la llumà } 0 \\
\text { coca a la calda }\end{array}$ & $\begin{array}{l}\text { Orden 4/2019, de } 7 \\
\text { de febrero, de la } \\
\text { Conselleria de } \\
\text { Educación, } \\
\text { Investigación, Cultura } \\
\text { y Deporte, por la que } \\
\text { se declaran Bien de } \\
\text { Relevancia Local } \\
\text { Inmaterial a las } \\
\text { Festes de l'Arbret } \\
\text { d'Altea: Arbret de } \\
\text { Sant Joan, Arbret de } \\
\text { Sant Roc i Arbret de } \\
\text { San Lluís (DOGV n. } \\
\text { 8486, de } 14 \text { de } \\
\text { febrero de } 2019 \text { ). }\end{array}$ \\
\hline
\end{tabular}




\begin{tabular}{|c|c|c|c|c|c|c|}
\hline Festividad & Lugar & Calendario & Conmemoración & $\begin{array}{c}\text { Cristiana, } \\
\text { pagana o } \\
\text { secular }\end{array}$ & $\begin{array}{c}\text { Preparaciones, comidas } 0 \\
\text { bebidas servidas } \\
\text { para la ocasión }\end{array}$ & Protección \\
\hline L'Escaldà & $\begin{array}{l}\text { Municipios de la } \\
\text { Marina Alta: } \\
\text { Jávea, } \\
\text { Benitachell, } \\
\text { Teulada, Benissa, } \\
\text { Jesús Pobre, } \\
\text { Llíber, Xaló, } \\
\text { Senija, Parcent, } \\
\text { la Xara y Gata de } \\
\text { Gorgos. En } \\
\text { l'Horta Nord se } \\
\text { escalda } \\
\text { testimonialmente } \\
\text { en Massarrojos } \\
\text { (Valencia). En la } \\
\text { Safor en Ador. En } \\
\text { la Vall d'Albaida } \\
\text { en Terrateig, } \\
\text { Montichelvo, } \\
\text { Benicolet y el } \\
\text { Palomar. }\end{array}$ & $\begin{array}{l}\text { Se realiza } \\
\text { anualmente entre } \\
\text { los meses de } \\
\text { agosto y } \\
\text { septiembre }\end{array}$ & $\begin{array}{l}\text { Proceso de } \\
\text { transformación de } \\
\text { la uva moscatel } \\
\text { en pasas }\end{array}$ & Pagana & $\begin{array}{l}\text { Uva moscatel y su } \\
\text { transformación en } \\
\text { pasas }\end{array}$ & $\begin{array}{l}\text { Decreto 120/2018, de } \\
3 \text { de agosto, del } \\
\text { Consell, declara Bien } \\
\text { de Interés Cultural } \\
\text { Inmaterial a l'Escaldà, } \\
\text { proceso de } \\
\text { transformación de la } \\
\text { uva moscatel en pasas } \\
\text { (DOGV n. } .^{\circ} 8371 \text {, de } \\
29 \text { de agosto de } \\
2018 \text { ). }\end{array}$ \\
\hline $\begin{array}{l}\text { Fogueres de } \\
\text { Sant Joan }\end{array}$ & Alicante & $\begin{array}{l}\text { Entre el } 20 \text { y el } 24 \\
\text { de junio }\end{array}$ & San Juan & Cristiana & $\begin{array}{l}\text { Portadas de } \\
\text { barracas con } \\
\text { motivos } \\
\text { gastronómicos }\end{array}$ & $\begin{array}{l}\text { Decreto 222/2014, de } \\
19 \text { de diciembre, del } \\
\text { Consell, por el que se } \\
\text { declaran Bien de } \\
\text { Interés Cultural } \\
\text { Inmaterial a Les } \\
\text { Fogueres de Sant } \\
\text { Joan de Alicante } \\
\text { (DOGV n. } .^{\circ} 7428 \text {, de } \\
22 \text { de diciembre de } \\
2014 \text { ). }\end{array}$ \\
\hline Fallas & Valencia & $\begin{array}{l}\text { Del } 14 \text { al } 19 \text { de } \\
\text { marzo }\end{array}$ & San José & Cristiana & $\begin{array}{l}\text { Buñuelos, Paella } \\
\text { valenciana, el } \\
\text { chocolate, la } \\
\text { horchata y els } \\
\text { fartons }\end{array}$ & $\begin{array}{l}\text { El Decreto 44/2012, de } \\
9 \text { de marzo, del } \\
\text { Consell, por el que } \\
\text { declara Bien de } \\
\text { Interés Cultural } \\
\text { Inmaterial a la Fiesta } \\
\text { de las Fallas de } \\
\text { Valencia (DOGV n. } \\
6732 \text {, de } 12 \text { de marzo } \\
\text { de 2012) }\end{array}$ \\
\hline $\begin{array}{l}\text { Fiesta de la } \\
\text { Santantonada } \\
\text { de Forcall }\end{array}$ & Forcall & $\begin{array}{l}\text { Mes de enero, el } \\
\text { fin de semana } \\
\text { más próximo a la } \\
\text { festividad de San } \\
\text { Antonio Abad (17 } \\
\text { de enero), } \\
\text { desarrollándose }\end{array}$ & San Antonio Abad & Cristiana & $\begin{array}{l}\text { Rifa del Corder, la } \\
\text { Pastà de la } \\
\text { Rotlleta, la Rostida } \\
\text { de Xulles y els } \\
\text { Botets }\end{array}$ & $\begin{array}{l}\text { Decreto 10/2012, de } 5 \\
\text { de enero, del Consell, } \\
\text { por el que se declara } \\
\text { Bien de Interés } \\
\text { Cultural Inmaterial a la } \\
\text { Fiesta de la } \\
\text { Santantonada de }\end{array}$ \\
\hline
\end{tabular}




\begin{tabular}{|c|c|c|c|c|c|c|}
\hline Festividad & Lugar & Calendario & Conmemoración & $\begin{array}{c}\text { Cristiana, } \\
\text { pagana } 0 \\
\text { secular }\end{array}$ & $\begin{array}{c}\text { Preparaciones, comidas c } \\
\text { bebidas servidas } \\
\text { para la ocasión }\end{array}$ & Protección \\
\hline & & $\begin{array}{l}\text { durante tres días: } \\
\text { viernes, sábado y } \\
\text { domingo. }\end{array}$ & & & & $\begin{array}{l}\text { Forcall (DOGV } \text { n. }^{\circ} \\
6688 \text {, de } 10 \text { de enero } \\
\text { de 2012). }\end{array}$ \\
\hline Albufera & Valencia & Todo el año & $\begin{array}{l}\text { Costumbre de } \\
\text { pesca navegación } \\
\text { a vela latina }\end{array}$ & Pagana & $\begin{array}{l}\text { all i pebre de } \\
\text { anguila }\end{array}$ & $\begin{array}{l}\text { Decreto 164/2016, de } \\
4 \text { de noviembre, del } \\
\text { Consell, por el que se } \\
\text { declara Bien de } \\
\text { Interés Cultural } \\
\text { Inmaterial a las } \\
\text { actividades } \\
\text { tradicionales de la } \\
\text { Albufera de Valencia: } \\
\text { la pesca artesanal y a } \\
\text { la navegación a vela } \\
\text { latina (DOGV n. } 7917 \text {, } \\
\text { de } 15 \text { de noviembre } \\
\text { de } 2016) .\end{array}$ \\
\hline $\begin{array}{l}\text { Peregrinaciones } \\
\text { de Les Useres y } \\
\text { Culla al } \\
\text { santuario de } \\
\text { Sant Joan de } \\
\text { Penyagolosa }\end{array}$ & $\begin{array}{l}\text { Les Useres y } \\
\text { Culla }\end{array}$ & $\begin{array}{l}\text { Les Useres: El } \\
\text { último viernes de } \\
\text { abril y el sábado } \\
\text { inmediato } \\
\text { Culla: se celebra el } \\
\text { viernes y sábado } \\
\text { pasada la fiesta de } \\
\text { la Santísima } \\
\text { Trinidad. }\end{array}$ & $\begin{array}{l}\text { Sant Joan de } \\
\text { Penyagolosa y Sant } \\
\text { Joan Baptista }\end{array}$ & Cristiana & $\begin{array}{l}\text { La fogassa de } \\
\text { Sant Joan, el } \\
\text { menú del } \\
\text { peregrino y la sopa } \\
\text { de cap }\end{array}$ & $\begin{array}{l}\text { Decreto 53/2016, de } \\
29 \text { de abril, del } \\
\text { Consell, por el que se } \\
\text { declaran Bien de } \\
\text { Interés Cultural } \\
\text { Inmaterial a las } \\
\text { peregrinaciones de } \\
\text { Les Useres y Culla al } \\
\text { santuario de Sant Joan } \\
\text { de Penyagolosa } \\
\text { (DOGV n. } .^{\circ} 7773 \text {, de } 3 \\
\text { de mayo de 2016). }\end{array}$ \\
\hline
\end{tabular}

Nota Elaboración propia.

En las Festes de l'Abret d'Altea: Arbret de Sant Joan, Arbret de Sant Roc i Arbret de Sant Lluís, se hace especial referencia a la gastronomía local, al mencionar el pan, morcilla, longaniza, melva, sangatxo, coca a la llumà o coca a la calda, comida típica alteana consistente en una masa horneada con verduras, embutidos, salazones (tocino, tomate maduro, tomate en salmorra, anchoa, morcilla o longaniza).

Durante el traslado del arbret se ofrece estos productos a los participantes, en forma de merienda. En el Arbret de Sant Joan, la merienda se brinda antes de comenzar el traslado, mientras que en los arbrets de Sant Roc y Sant Lluís se ofrecen varias meriendas a mitad de la realización del recorrido y después de la planta.

En L'Escaldà y la uva moscatel, y su transformación en pasas, se destaca a la pasa y su importancia histórica para la localidad: 
El dominio comercial y marítimo de Inglaterra en el siglo XIX supuso la expansión en el cultivo, producción, transformación y comercialización de la pasa en la Marina Alta, y se extendió después a las comarcas centrales como la Safor y la Vall d'Albaida, hasta la misma puerta de la capital del Turia, València, como así lo testimonia el gran riurau del Mas del Fondo de Massarrojos. Así las cosas, la uva moscatel se constituyó en monocultivo de las tierras centro meridionales valencianas, con una estructura económica volcada en la exportación, ya que su comercialización se expandió desde Europa hasta África y América, y dio lugar a la proliferación de casas señoriales y burguesas, la ampliación del puerto como el de Dénia con el muelle de la Pansa, el aumento del tráfico marítimo, el ferrocarril de Dénia a Carcaixent, la construcción de almacenes, el asentamiento de extranjeros y la proliferación de viceconsulados, la introducción de la libra esterlina y sistemas de contratación, o la elaboración de cajas de madera, camisas y cromos modernistas que identificaban las pasas de diferente calibre, categoría y destino, y que se constituyeron en la principal materia prima de la gastronomía inglesa (plumcake y pudding).

Adicionalmente, el escaldado y la producción de la pasa forman parte de la cultura de dicho territorio, que se ha perpetuado en la arquitectura: los riurau (construcción típica tradicional de la comarca de la Marina que se utiliza para el secado de la uva pasa); también de la gastronomía tradicional; tenemos el arroz al horno con pasas o las tortas con pasas; se suman los vinos y mistelas (bebida elaborada con la uva y que se suele tomar en el postre, ya que es dulce).

A propósito de lo mencionado, se contemplan acciones para la recuperación del cultivo del moscatel, creando espacios para productores locales en Jesús Pobre, la denominación de origen y el proyecto biomoscatel iniciada por Benitachell, la inmersión de la pasa y su gastronomía en Denia y Marina Alta Tasting Life, patrimonio inmaterial de la UNESCO; o bien la ruta de los riuraus, para divulgar L'Escaldà, el cultivo del moscatel, y la comercialización de pasas, caldos y mistelas. Junto a ello, destaca la Fiesta del Moscatel en Teulada que, desde el año 1984, organiza la asociación cultural amigos de dicha localidad, dedicando jornadas al conocimiento y divulgación del moscatel, con L'Escaldà en un riurau tradicional, con cata de vinos y mistelas, degustación de uva y la cabalgata del moscatel.

Mención aparte merece Les Fogueres de San Joan, en Alicante y las portadas de barraca, que desde su creación, la primera en el año 1931, incluye motivos gastronómicos en su diseño, en relieve o tridimensional. Realizadas por los artistas de hogueras o por la propia comisión, son una carta de presentación.

De otro lado, en Fallas de Valencia se vinculan la indumentaria, la gastronomía y la pirotecnia. Aunque no se especifican los platos de la gastronomía durante esta fiesta fallera, sí se conocen algunas manifestaciones propias como la paella, los buñuelos (dulce elaborado con masa de harina frita y espolvoreados de azúcar), el chocolate, la horchata (bebida refrescante elaborada con chufa, que es un tubérculo que se cultiva en la huerta valenciana) y els fartons (un dulce en forma de bollito alargado que se consume mojándolo en la horchata, y que está elaborado con un masa suave compuesto de harina, leche, azúcar, aceite, levadura y huevos; que se adorna con azúcar glaseada por encima). 
En la Fiesta de la Santantonada de Forcall durante la celebración «se articulan elementos materiales e inmateriales, combinando y entremezclando teatro popular, fuegos la víspera, figuras simbólicas del bestiario infernal tradicional, componentes carnavalescos, elementos pirotécnicos, gastronomía compartida» (Decreto 10/ 2012). Se destaca la pastada de la rolleta, donde se reúnen las mujeres para elaborar los dulces típicos (p. ej., rollitos); la rifa del cordero: paseo del animal adornado de un pañuelo bordado, collar, cascabeles y campanillas. Durante esta fiesta se realiza una comida popular, rostida de xulles, asado de chuletas junto con pan, olivas, vino y alioli (una salsa elaborada con ajo y aceite), en la rifa del cordero se venden papeletas y se realizan juegos y competencias en las que se premia con animales (conejos y aves de corral), la llaman els Botets, consiste en saltar botas de vino medio infladas con los pies juntos. Las ollas, es otra actividad, participan los niños, con un palo intentan romper la olla de barro para obtener las golosinas, como una especie de piñata.

Asimismo, la gastronomía está presente en las peregrinaciones de Les Useres y Culla al santuario de Sant Joan de Penyagolosa: la fogassa de Sant Joan, el menú del peregrino y la sopa de cap o sopa de cabeza (su nombre se debe a que cuando los peregrinos la tomaban, veían reflejada su cabeza en el agua); imprescindibles a lo largo de las mismas.

En la peregrinación de Les Useres, se indica que el depositario acompaña a los clavarios en el reparto de los trozos del pan bendecido. La denominada fogassa o hogaza de Sant Joan es bendecida el anterior jueves por la tarde en Chodos y en Les Useres, antes de la llegada de los peregrinos. Se lleva en las acémilas y en el Filador o Corral Roig; la reparten entre los congregados como un símbolo de participación del pueblo en la celebración. Los alimentos que se llevan durante la peregrinación son vino, pan, lechugas de ensalada, tortillas y huevos cocidos, arroz, judías cocinadas, bacalao desmenuzado y frito.

En el Decreto 53/2016, respecto a los días, se menciona:

[el viernes] «después de la misa y antes de salir de Les Useres, alguna porción de chocolate o unos higos, todo acompañado de una copa de aguardiente (bebida alcohólica destilada de fermentado alcohólico).

Almuerzo en el paraje de La Savina: un pan y dos huevos hervidos o crudos, vino y agua.

Comida en Sant Miquel de les Torrocelles: ensalada de lechuga aderezada con aceite y vinagre, un huevo hervido o crudo, arroz con bacalao, bacalao con salsa de canela, aceitunas, pan, vino y agua.

Merienda en la Font dels Posso: un pan, una tortilla, un huevo duro o crudo, aceitunas, vino y agua.

Cena en Sant Joan: ensalada de lechuga con aceite y vinagre, un huevo duro o crudo, sopa de pan, judías a la vinagreta, aceitunas, pan, vino y agua.

Sábado: Comida: lo mismo que el día anterior en Sant Miquel de les Torrocelles.

Merienda: lo mismo que el día anterior en la Font dels Possos. 
Antiguamente la gente del pueblo y los masos solían aportar harina, aceite, huevos, etc., pero en la actualidad hacen una aportación económica.

En cuanto a la peregrinación de Culla, que se conoce como Processó de Culla a Sant Joan de Penyagolosa o Processó de Culla a Sant Joan de la Font Coberta, se menciona el almuerzo a base de sopas, con agua clara hirviendo, pan seco, un huevo crudo, que se escalda y un poco de aceite y sal. Como se lee en el Decreto 53/ 2016: «allí, en tiempo pasado, el ermitaño tenía la costumbre de preparar agua hirviendo que los de Culla aprovechaban para hacer las sopas. Los peregrinos decían que comían sopa de cap porque al asomarse a la olla veían reflejada su cabeza en el agua».

Para culminar, el Decreto 53/2016 se refiere también a la Font de Santa María, en el que se realiza un descanso refrigerio a base de bacalao, tomates y pan.

\section{Influencia de la gastronomía: recurso turístico y declaración de interés turístico. El caso de la Comunitat Valenciana}

En la Comunitat Valenciana, al hablar de gastronomía y territorio, es inevitable no mencionar productos que inmediatamente se vinculan con la identidad del territorio, por ejemplo, la paella: plato tradicional valenciano compuesto de arroz, verduras, conejo y pollo, al que se le suele añadir caracoles, también lo elaboran con caldo de pescado, gambas, cigalas y sepia, denominándose paella marinera (Valencia); la horchata: bebida refrescante elaborada con chufa (Alboraya); los flaons: dulce típico elaborado con una masa dulce sin fermentar requesón y almendras, tiene forma de empanadilla de media luna, aromatizada con mistela, aguardiente o anís, y se espolvorea por encima con azúcar y canela (Morella); el arnadí: dulce elaborado con calabaza y almendras (Xàtiva), entre otros. Precisamente todos estos platos típicos a los que hemos hecho alusión, no están protegidos dentro de un Bien de Interés Cultural (para la tan conocida paella se están realizando los trámites), y sin embargo, sí están íntimamente unidos a los lugares, al territorio donde se suelen degustar.

La Ley 15/2018, de 7 de junio, de turismo, ocio y hospitalidad de la Comunitat Valenciana (BOE n. ${ }^{\circ}$ 157, de 29 de junio de 2018), se refiere a la gastronomía como un recurso turístico, siempre que sea expresivo de la Comunitat y genere flujos turísticos.

Los recursos turísticos de primer orden son los elementos que de forma aislada, o en conjunto, pueden generar por sí mismos flujos y corrientes de turismo; que contribuyen a reforzar la imagen de marca turística de la Comunitat Valenciana y su promoción como destino turístico.

Las fiestas de interés turístico se regulan por el Decreto 119/2006, de 28 de julio, del Consell, regulador de las declaraciones de fiestas, itinerarios, publicaciones y obras audiovisuales de interés turístico de la Comunitat Valenciana (DOGV n. ${ }^{\circ}$ 5315, de 01 de agosto de 2006), junto con el Decreto 20/2015, de 4 de noviembre, del president de la Generalitat, regulador del procedimiento electrónico para la declaración de fiestas, itinerarios, publicaciones y obras audiovisuales de interés turístico de la Comunitat Valenciana (DOGV n. ${ }^{\circ}$ 7654, de 10 de noviembre de 2015), con el objetivo de revisar los requisitos y procedimientos para la declaración de una fiesta como de interés turístico (Generalitat Valenciana, 2020). 
Se consideran Fiestas de Interés Turístico de la Comunitat Valenciana a «los certámenes, fiestas o acontecimientos que se celebren en el territorio de ésta y que, ofreciendo una especial relevancia desde el punto de vista turístico, supongan una valoración de la cultura y de las tradiciones populares» (Decreto 119/2006). Y, de carácter gastronómico, con base en productos representativos de la Comunitat Valenciana o vinculados a su economía; con una antigüedad mínima, por lo menos de diez años, y acreditadas por un organismo o entidad competente.

En las fiestas de interés turístico, la legislación no establece una prioridad de características de ámbito cultural o económico en sus preceptos. No obstante, en el art. 4 del Decreto 119/2006 se señala una serie de requisitos para que se le declare Fiesta de Interés Turístico de la Comunitat Valenciana. Debe indicarse el arraigo o tradición popular de la fiesta, la originalidad de la celebración, mencionando los elementos esenciales que la hacen peculiar y singular respecto de otras; cómo reflejan la idiosincrasia del lugar y el valor cultural, gastronómico, lúdicofestivo o ambiental. Ese valor gastronómico se concibe de esta manera:

Manifestaciones típicas que impliquen tanto la elaboración como la exposición, degustación y venta de alimentos y bebidas propios de una determinada zona de la Comunitat Valenciana. Asimismo, está presente en aquellos casos en que se festeja el cosechado, recolección o vendimia de un determinado producto, siempre que sea de relevancia para la economía del lugar. (Decreto 119/ 2006)

Con referencia a la antigüedad, la fiesta debe tener al menos quince años. Pero, como se menciona anteriormente cuando tiene carácter gastronómico y se basa en productos representativos del lugar o vinculados a la economía, se reduce a diez años. Se suma la capacidad de atracción de visitantes o repercusión de la celebración, señalando que debe ser periódica y en fecha fácilmente determinable.

En suma, requisitos que se deben cumplir para que se declare Fiesta de Interés Turístico; no hay una jerarquía o prioridad, deben darse todos los requisitos indicados.

En cuanto a la tramitación, se pueden recabar informes de instituciones, entidades, organismos y personas de reconocido prestigio para apreciar el valor gastronómico de una determinada celebración o itinerario.

Las fiestas de interés turístico, relacionadas con la gastronomía, declaradas en la Comunitat Valenciana son las siguientes:

a. Fiestas de interés turístico autonómico. La fira de tots sants o feria de todos los santos (Cocentaina); Muestra del embutido artesano y de calidad (Requena); Festa de la Carxofa o Fiesta de la Alcachofa (Benicarló); El primer corte de la miel (Ayora); El día de las paellas (Benicàssim).

b. Fiestas de interés turístico provincial. El porrat de Sant Blai o San Blas (Potríes); Les calderes (Amassora); Festa del Rotllo (L’Alcora) Cant de la Carxofa o Alcachofa (Alaquàs); La Font del vi (Burriana) Feria (Nules); Feria de la cereza (Caudiel); Nit de la xulla o de la chuleta (Vila-Real); Fira de la cirera o Feria de la cereza, art i tradición (La Salzadella). 
c. Fiestas de interés turístico local. Feria valenciana de la miel (Montroy); Porrat de Sant Macià (Rótova); Porrat de Sant Antoni (Benirredrà); Fira y porrat de Sant Antoni (Benissa); Fira gastronómica i artesanal (Tàrbena); La merenguina (Llíria); el vole y la bacalà (Jérica) y Festa cassoletes (Castelló de Rugat).

\section{Factores a tener en cuenta para elegir un destino turístico gastronómico}

Existen factores que deben considerarse para elegir un destino turístico en el que la gastronomía esté presente (Royo, 2011; Sanz et al., 2017).

\section{Satisfacción del comensal como elemento clave}

La existencia de tradiciones, costumbres, productos, su forma de elaboración constituyen el patrimonio gastronómico de un lugar (Aguirregoitia y Fernández-Poyatos, 2017). Esta imagen construida por una gastronomía única del territorio, así como los hábitos y las tradiciones en la elaboración de los manjares son factores a tener en cuenta para que el turista se vea impresionado y determine su elección por la oferta (Hernández et al., 2015). En el caso de los bienes declarados de interés cultural inmaterial o de relevancia local, el turista puede sentirse atraído por conocer la fiesta y la gastronomía asociada. En este caso su satisfacción es anterior incluso a su consumo, ya que su deseo es precisamente asistir a la fiesta y consumir los productos gastronómicos típicos de la misma (Andrés, 2017).

\section{La gastronomía como marca de destino: los productos con denominación de origen protegida, indicación geográfica protegida y marca de calidad}

El turista puede encontrar como factor para la elección de su destino los productos protegidos. En este caso nos referimos a los productos con denominación de origen protegido, indicación geográfica protegida o con marca de calidad (Ramón, 2002; Ramón y Hernández, 2010; Ramón y Saz, 2003; Ramón, 2013a, Koerich et al., 2018).

El turista quiere tener confianza en la calidad de esos productos que pueden ir asociados también a la fiesta o a la ruta turística que decide realizar. Por ejemplo, en la fiesta de la Alcachofa de Benicarló, cuyo producto se regula por Orden 26/2010 de 15 de julio, de la Conselleria de Agricultura Pesca y Alimentación por la que se aprueba el texto del Reglamento de la Denominación de Origen Protegida Alcachofa de Benicarló y su consejo regulador (DOGV n. ${ }^{\circ}$ 6321, de 29 de julio de 2010).

\section{La promoción del destino: sellos, publicidad, series, películas}

El turismo gastronómico es también un turismo experiencial y de sensaciones. Atrae al turista y lo motiva a conocer un lugar donde la gastronomía juega un papel principal al ver un anuncio publicitario, o presenciar una campaña de publicidad o marketing (Camacho, 2017; Fusté, 2017; Mestre y Molés, 2019); también, al presentar un plato o potaje junto a las imágenes en una serie o película (Bigné, 2011). Esto se convierte en un potente foco de atracción; el turista va a querer conocer el sitio, la localidad, al asociarlo con los personajes que han degustado el producto. Incluso, en algunos casos, los sellos de correos en los que aparece un producto gastronómico 
puede ser un factor de influencia para el turismo; igualmente, el uso de las tecnologías de información y comunicación (TIC) y las redes sociales, como el WhatsApp (Clemente, 2017; Navarro y Xavier, 2018; Romero et al., 2017).

\section{Las ferias medievales y gastronómicas}

Estas, son atractivos visuales en los que se recrean productos típicos; se centran en los productos más conocidos de la localidad.

\section{Las rutas gastronómicas}

Según indica el Decreto 119/2006, se consideran Fiestas de Interés Turístico (art. 2), a los acontecimientos de índole festivo, cultural, gastronómico que supongan:

a. La integración y participación de la sociedad local.

b. La afluencia e integración de visitantes y turistas.

c. La potenciación, conservación y difusión de valores positivos de convivencia, tolerancia y reconocimiento de la diversidad.

d. La promoción tanto del territorio en el que se desarrollan como de sus valores culturales, lúdico-festivos, histórico-artísticos, paisajísticos, urbanísticos y medioambientales, ya sea en el ámbito de la Comunitat Valenciana o fuera de ella.

Se señala que los itinerarios de Interés Turístico de la Comunitat Valenciana son:

Aquellos que, transcurriendo mayoritariamente por el territorio de ésta, permitan al turista descubrir la historia, cultura, patrimonio, arquitectura, gastronomía u otros análogos propios de la Comunitat Valenciana y que, singular y globalmente considerados, se erijan como recurso turístico dentro de la oferta turística de la Comunitat Valenciana.

Con respecto a los itinerarios gastronómicos, es importante que se trate de lugares donde puedan degustarse productos que hayan sido avalados y protegidos, preferentemente, por una denominación de origen.

En el caso de la Huerta de València, el Decreto 219/2018, de 30 de noviembre, del Consell, por el que se aprueba el Plan de acción territorial de ordenación y dinamización de la Huerta de València (DOGV n. ${ }^{\circ}$ 8448, de 20 de diciembre de 2018), en su art. 77, hace mención de la red gastronómica, con la finalidad de que el Consejo de la Huerta de València lo cree para promover la gastronomía tradicional del lugar y la realización de actividades encaminadas a impulsar su conocimiento y difusión (Ramón, 2011, 2013b).

Los establecimientos de restauración deben ajustarse a lo indicado en el art. 42 del Decreto 219/2018 relativo a los alojamientos turísticos y establecimientos de restauración. Las instalaciones de estos establecimientos en alquerías, masías u otras construcciones rurales deben realizarse con especial protección. 
Es menester fomentar el consumo de productos frescos en los restaurantes y otros centros públicos o privados donde concurra el público.

Las rutas gastronómicas han sido un factor clave para la elección del destino; por ello son numerosas las rutas que se han creado en la Comunitat Valenciana en torno a la gastronomía. Son muy conocidas las rutas a las principales bodegas con degustación incluida, la ruta de la tapa, la ruta de la cuchara, la ruta de la trufa, entre otras muchas (Camacho y Mejía, 2018; García y Sánchez, 2018; López-Guzmán y Margarida, 2011; Ramón et al., 2013; Salvado et al., 2019).

\section{Las estrellas y soles michelín, y los restaurantes}

El turista gastronómico puede verse atraído por degustar platos típicos en los restaurantes que poseen estrellas y soles michelín. La doctrina ha diferenciado entre el turista que dispone de recursos y acude a estos lugares porque es un apasionado de la gastronomía, deseoso de probar platos minimalistas y el turista que solo acude por lo que se denomina 'el postureo', o por el hecho de comentar que ha estado en uno de los restaurantes galardonados con ese indicativo (Aguirregoitia y Fernández-Poyatos, 2019).

Para Hernández et al. (2019) es un reclamo atractivo para el turismo gastronómico y, unido a los bienes declarados como de interés cultural inmaterial o relevancia local de una localidad, puede incrementar el número de visitantes.

\section{Los mercados tradicionales}

Otro de los factores que influye en la decisión del destino turístico, por parte de los interesados en la gastronomía, es la visita a los mercados tradicionales (García, 2017). El Mercado Central es uno de los más conocidos en la Comunitat Valenciana, declarado como bien de interés cultural. Se le menciona en el Decreto 169/2007, de 28 de septiembre, del Consell, por el que se culmina la primera fase de actualización y adaptación de la Sección Primera del Inventario General del Patrimonio Cultural Valenciano con la declaración como Bienes de Interés Cultural de determinados bienes inmuebles.

En el mencionado mercado, ubicado en la ciudad de Valencia, en el centro histórico peatonalizado, el turista gastronómico es asiduo visitante. Por lo que representantes del Mercado Central, las concejalías de turismo y comercio, la asociación de guías y València Turisme firmaron el Protocolo de Buenas Prácticas para el Turismo en el Mercado Central (Mercat Central de Valencia, 2018), que incluye los siguientes puntos: (a) acreditación de los guías con su identificación de guía oficial, de conformidad con la normativa aplicable; (b) explicación sobre el mercado previo a la entrada; (c) determinación de un punto de encuentro; (d) adecuada señalética en el mercado, de las puertas de acceso y servicios, y en varios idiomas; (d) establecimiento de normas básicas de comportamiento en la visita al mercado (no tocar el género, fotografías solo en los puestos que lo permiten y no obstaculizar los pasillos). 


\section{Conclusiones}

La gastronomía como manifestación cultural está presente en la Declaración de los Bienes de Interés Cultural de la Comunitat Valenciana, España. Donde se menciona a la gastronomía como producto local identitario del territorio o como alimento a consumir durante el peregrinaje. En todos los casos, forma parte del bien al declararse su protección.

Aún así, llama la atención que platos indiscutiblemente típicos y alimentos vinculados a la Comunitat Valenciana, como son la paella o la horchata no se reconozcan como bienes de interés cultural inmaterial. Aunque ya está en marcha una iniciativa, aún no se han declarado como tales. Precisamente, la declaración como bien de interés cultural o bien de relevancia local aumenta la protección, conservación y difusión del bien, por ejemplo, en la elaboración de un plato típico se evita usar ingredientes distintos a los clásicos, al ser un obstáculo para que se le denomine como tal. Desde luego, es el caso la paella.

La gastronomía, como factor de elección de un destino turístico, también se vincula a la denominación de origen de los productos, caso del vino, por ejemplo; también, a la denominación de origen protegido, indicación geográfica protegida o a la marca de calidad de un producto. Esto, incrementa la posibilidad de que el visitante se sienta atraído por la degustación de productos típicos que son reconocidos por su calidad.

Es importante hacer mención al destino, ya que el turista gastronómico puede descubrir nuevos lugares asociados a la gastronomía y productos típicos; un destino turístico caracterizado por otras singularidades y no solo por ser una oferta gastronómica (De Jesús et al., 2017; Fandos y Flavián, 2011; Franco, 2018). La gastronomía aquí juega un papel dinámico que atrae, más allá del turismo de sol y playa; constituyéndose en un elemento clave para elegir un destino (Daries et al., 2018; Hernández y Jacinto, 2019). En buena cuenta, adquiere valor de marca en el territorio (Clemente et al., 2009; Vázquez, 2016).

No menos trascendente es el perfil del turista que se relaciona con el producto ofrecido; por ejemplo, un turista sibarita, un gastrónomo, un gourmet, que combina la fiesta protegida con un bien de interés cultural inmaterial o de relevancia local; asociando la fiesta con los productos a degustar, que se siente parte integrante de ella. Se trata de turistas de gastronomía de diferentes niveles, dispuestos a valorar sus experiencias, priorizando la calidad antes que la cantidad, que disfrutan la creatividad, la puesta en escena y descubrir nuevos sabores (Daries et al., 2018).

\section{Agradecimientos}

Trabajo realizado en el marco del Proyecto I+D+i «Retos investigación» del Programa estatal de I+D+i orientado a los Retos de la Sociedad del Ministerio de Ciencia, Innovación y Universidades: RTI2018-097354B-100, y Proyecto de I+D+i Retos MICINN (PID2019-108710RB-I00, 2020-2022). 


\section{Referencias}

Aguirregoitia, A. y Fernández-Poyatos, M. D. (2017). La gastronomía como recurso turístico en la provincia de Alicante. International journal of scientific management and tourism, 3(3), 25-45. http://www.ijosmt.com/index.php/ijosmt/article/view/246/234

Aguirregoitia, A. y Fernández-Poyatos, M. D. (2019). La simplicidad como proceso creativo culinario: una tendencia en el turismo gastronómico. Pasos: Revista de Turismo y Patrimonio Cultural, 17(5), 875-888. https://riull.ull.es/xmlui/bitstream/handle/915/16536/ PS_17_5_\%282019\%29_01.pdf?sequence=1\&isAllowed=y

Alonso, D. (2018). Identidad cultural y turismo gastronómico: la mercantilización del patrimonio. International journal of scientific management and tourism, 4(2), 51-71. http://www.ijosmt.com/index.php/ijosmt/article/view/349/347

Andrés, F. (2017). Gastronomía, turismo y potencialidades territoriales: el plato minero y la salazón, bases para el turismo alimentario en Nemocón. Cuadernos de Geografía: Revista Colombiana de Geografía, 26(2), 295-306. https://revistas.unal.edu.co/index.php/ rcg/article/view/59280/pdf

Bahls, Á. A., Wendhausen, R. y Da Silva, E. (2019). Comprensión de los conceptos de culinaria y gastronomía: una revisión y propuesta conceptual. Estudios y perspectivas en turismo, 28(2), 312-330. http://www.estudiosenturismo.com.ar/PDF/V28/N02/v28n2a04.pdf

Bigné, J. E. (2011). Las respuestas del turista ante la imagen del lugar de origen del producto. En Prensa Universitarias de Zaragoza (Eds.), Turismo Gastronómico: Estrategias de marketing y experiencias de éxito (pp. 51-68).

Camacho, M. (2017). Museos del chocolate en Europa, historia, marketing y turismo. El Periplo Sustentable: revista de turismo, desarrollo y competitividad, 33, 658-689. http://www.scielo.org.mx/scielo.php?script=sci_arttext\&pid=S1870-90362017000200658

Camacho, M. y Mejía, M. I. (2018). Turismo gastronómico del cacao y el chocolate, tendencias Latinoamericanas. Gran Tour, 18, 5876. https://eutm.es/grantour/index.php/grantour/article/view/47/19

Clemente, J. S. (2017). La experiencia del turista en el consumo de paella en las arrocerías de Valencia mediante netnografía. International journal of world of tourism, 4(7), 27-34. https://idus.us.es/bitstream/handle/11441/77030/Laexperiencia\%20del\%20turista\%20 en\%20el\%20consumo\%20de\%20paella\%20en\%20las\%20arrocer\%c3\%adas\%20de\%20Valencia\%20mediante\%20netnograf \%c3\%ada.pdf?sequence $=1 \&$ isAllowed $=\mathrm{y}$

Clemente, J. S., Roig, B., Valencia, S., Rabadán, M. T. y Martínez, C. (2009). Estudio del turismo gastronómico de Valencia. En Universidad de Granada (Eds.), Sociología del ocio y del turismo: tipos, planificación y desarrollo (pp. 87-102).

Daries, N., Ferrer-Rosell, B. Cristóbal, E. y Mariné, E. (2018). ¿Postureo o disfrute de la experiencia gastronómica? Efectos de la reputación y la experiencia en la recomendación de los restaurantes de alto nivel. Cuadernos de turismo, 42, 119-136. https://revistas.um.es/ turismo/article/view/353421/252791

De Jesús, D., Thomé, H., Espinoza, A. y Vizcarra, I. (2017). Turismo agroalimentario: una perspectiva recreativa de los alimentos emblemáticos desde la geografía del gusto. Estudios y perspectivas en turismo, 26(3), 549-567. http://ri.uaemex.mx/bitstream/handle/ 20.500.11799/67269/Turismo\%20Agroalimentario.pdf?sequence=1\&isAllowed=y

Fandos, C. y Flavián, C. (2011). Hacia la nueva cultura del turismo gastronómico. En Prensa Universitarias de Zaragoza (Eds.), Turismo Gastronómico: Estrategias de marketing y experiencias de éxito (pp. 11-30).

Franco, F. (2018). Patrimonio gastronómico y turismo. Publicaciones de la Institución Tello Téllez de Meneses, 89, 303-309.

Fusté, F. (2015). El turisme grastronòmic: autenticitat i desenvolupament local en zones rurals. Documents d'anàlisi geográfica, 61(2), 289-304. https://dag.revista.uab.es/article/view/v61-n2-fuste/218-pdf-ca

Fusté, F. (2017). La gastronomía en el Marketing turístico. Anais Brasileiros de Estudos Turísticos, 7(3), 88-99.

García, B. (2017). Los mercados de abastos y su comercialización como producto de turismo de experiencias. El caso de Madrid. Cuadernos de turismo, 39, 167-189. https://digitum.um.es/xmlui/handle/10201/53168

García, B. y Sánchez, I. (2018). La ruta milenaria del atún: lecciones aprendidas de un producto turístico experiencia en el litoral gaditano. International journal of world of tourism, 5(9), 1-15. https://dialnet.unirioja.es/servlet/ejemplar?codigo=494791\&info=open _link_ejemplar

Generalitat Valenciana. (15 de septiembre 2020). Listado de fiestas de interés turístico de la Comunitat Valenciana declaradas por la Generalitat. http://www.turisme.gva.es/turisme/es/files/pdf/FITCV_2020.pdf 
Hernández, J. R. y Jacinto, M. (2019). Potenciant un turismo cultural atractiu pel patrimonio de Llíria més enllà dels pilars tradicionals d'arqueologia, bandes de música i fires gastronòmiques: Turisme 2.0. Culturas: Revista de Gestión Cultural, 6(1), 1-17. https:// polipapers.upv.es/index.php/cs/article/view/11010/11491

Hernández, J. M., Di Clemente, E. y López, T. (2015). El turismo gastronómico como experiencia cultural. El caso práctico de la ciudad de Cáceres (España). BAGE: Boletín de la Asociación de Geógrafos Españoles, 68, 407-428. https://bage.age-geografia.es/ojs/ index.php/bage/article/view/1868/1784

Hernández, E. D., Balderas, A. y Alonso, D. (2019). Gastronomy: A customer study of restaurant in Córdoba (Spain) included in a prestiguious guide. Revista Internacional de Turismo y Empresa. RITUREM, 3(2), 131-145. https://helvia.uco.es/xmlui/bitstream/ handle/10396/19263/riturem_3_2_7.pdf?sequence=1\&isAllowed=y

Koerich, G. H., Perassi, R. y Pereira, F. A. (2018). Gastronomía como identidade de marca para destinos turísticos em ciudades creativas. CULTUR: Revista de Cultura e Turismo, 2, 88-104. https://periodicos.uesc.br/index.php/cultur/article/view/2294

López-Guzmán, T. y Margarida, M. (2011). Turismo, cultura y gastronomía. Una aproximación a las rutas culinarias. Tourism \& Management Studies, 1, 915-922. https://www.redalyc.org/articulo.oa?id=388743867083

Maldonado-Erazo, C. P., Álvarez, J., Del Río, M. C. y Mora, V. L. (2019). Gastronomía creativa: análisis de la producción científica. Estudios y perspectivas en turismo, 28(1), 61-79. http://www.estudiosenturismo.com.ar/PDF/V28/N01/v28n1a04.pdf

Martín, D. (2008). La gastronomía como patrimonio cultural inmaterial en el turismo. En Centro Internacional para la Conservación del Patrimonio (Eds.), IX Congreso Internacional de Rehabilitación del Patrimonio Arquitectónico y Edificación (pp. 113-118).

Mercat Central de Valencia. (2018). Protocolo de buenas prácticas para el turismo en el Mercado Central. https:// www.mercadocentralvalencia.es/NoticiasWeb/VerNoticia?NoticiaId=1645

Mestre, E. M. y Molés, T. (2019). Promoción de ciudades Patrimonio de la Humanidad: estudio sobre la traducción del léxico relacionado con la gastronomía. Quaderns de filología. Estudis Lingüístics, 24, 329-347. https://ojs.uv.es/index.php/qfilologia/article/view/16315/ 14797

Monllor-Rico, N. y Soy-Massoni, E. (2018). El pasturisme: turismo vivencial a les explotacions ramaderes de pastura de les comarques gironines. Quaderns agraris, 44, 93-115. http://revistes.iec.cat/index.php/QA/article/view/144805/143423

Navarro, G. y Xavier, F. (2018). Sellos, turismo y gastronomía: El papel de la gastronomía en la promoción turística de España a través de los sellos de correos. Pasos: Revista de Turismo y Patrimonio Cultural, 16(4), 927-938. https://riull.ull.es/xmlui/bitstream/handle/ 915/10789/PS_16_4_\%282018\%29_04.pdf?sequence=1\&isAllowed=y

Plan Nacional de Salvaguarda del Patrimonio Cultural Inmaterial. (2015). Madrid: Secretaría General Técnica. Centro de Publicaciones. Ministerio de Educación, Cultura y Deporte. https://sede.educacion.gob.es/publiventa/plan-nacional-de-salvaguarda-del-patrimoniocultural-inmaterial/patrimonio-historico-artistico/20710C

Ramón, F. (2002). La regulación de la marca de calidad «CV» en los productos agrarios y agroalimentarios de la Comunidad Valenciana. En Universidad de La Rioja (Eds.), Régimen jurídico de la seguridad y calidad de la producción agraria. IX Congreso Nacional de Derecho Agrario (pp. 255-264).

Ramón, F. (2011). La recuperación del patrimonio y los recursos naturales y culturales del medio rural. En Universitat Politècnica de València (Eds.), Actes del III Congrés d'Estudis de l'Horta Nord 8 (pp. 729-741).

Ramón, F. (2012a). El patrimonio cultural. Régimen legislativo y su protección. Tirant lo Blanch.

Ramón, F. (2012b). La declaración de bienes de interés cultural inmaterial y su regulación en la legislación sobre patrimonio cultural valenciano. En Ediciones del Orto (Eds.), América Latina, globalidad e integración (pp. 1535-1546).

Ramón, F. (2013a). Las marcas de calidad y las denominaciones de origen de los productos agrarios y agroalimentarios. En Tirant lo Blanch (Eds.), El Derecho agrario valenciano y su aplicación a la empresa familiar agroalimentaria y los usos del suelo: aspectos jurídicos y económicos (pp. 157-214).

Ramón, F. (2013b). La huerta valenciana y su revitalización como opción turística a través del diseño de rutas guiadas. En Tirant lo Blanch (Eds.), Espacios de ocio y deporte como dinamizadores turísticos. XVI Congreso Internacional de Turismo UniversidadEmpresa (pp. 345-356). 
Ramón, F., Canós, L. y Santandreu, C. (2013). Turismo enológico en la Comunidad Valenciana: el caso de bodegas Vicente Gandía. En Tirant lo Blanch (Eds.), Espacios de ocio y deporte como dinamizadores turísticos. XVI Congreso Internacional de Turismo Universidad-Empresa (pp. 431-444).

Ramón, F. (2014). El patrimonio cultural valenciano: estudio de casos y su protección. Revista jurídica valenciana. Associació de Juristes Valencians (anteriormente Revista Internauta de Práctica Jurídica), 31(3), 1-22. http://www.uv.es/ajv/art_jcos/art_jcos/ num31-2/1frapatri.pdf

Ramón, F. (2016). Protección del patrimonio cultural inmaterial. Revista General de Legislación y Jurisprudencia, 4, 639-670.

Ramón, F. (2018). Del turismo sostenible al ecoturismo: una perspectiva legal. En Aranzadi Thomson Reuters (Eds.), Turismo y sostenibilidad (pp. 171-197).

Ramón, F. y Hernández, A. (2010). La marca de calidad «CV» para productos agrarios y agroalimentarios. Revista de Derecho civil valenciano, 7, 1-9. http://www.derechocivilvalenciano.com/index.php?option=com_content\&task=view\&id=71\&Itemid=29

Ramón, F. y Saz Gil, M. I. (2003). La marca de calidad como ventaja competitiva del cooperativismo agrario. En Universitat Politècnica de València (Eds.), Libro de Actas del Encuentro Nacional de Institutos y Centros Universitarios de Investigación en Economía Social (pp. 1-11).

Real Academia Española. (2020). Voz «gastronomía». https://dle.rae.es/gastronom\%C3\%ADa

Reyes, A. C., Guerra, E. A. y Quintero, J. M. (2017). Educación en gastronomía y su vínculo con el turismo. El Periplo Sustentable: revista de turismo, desarrollo y competitividad, 32. http://www.scielo.org.mx/scielo.php?script=sci_arttext\&pid=S187090362017000100009\&lng=es\&nrm=iso\&tlng=es

Romero, M., Casado, A. M. y Alarcón, P. (2017). Factores que influyen en el uso de whatsapp como canal para la toma de decisión en el consumo gastronómico. International journal of scientific management and tourism, 3(3), 447-466.

Royo, M. (2011). El producto agroalimentario como atributo de importancia en la formación de la imagen del destino turístico. En Prensa Universitarias de Zaragoza (Eds.), Turismo Gastronómico: Estrategias de marketing y experiencias de éxito (pp. 69-92).

Salvado, J., Ferreira, A. M., Serra, J. y Marujo, N. (2019). Gastronomia de Taberna \& Storytelling: Saberes e Sabores que reforçam a identidade cultural do territorio. Revista portuguesa de estudos regionais, 50, 65-84. http://www.apdr.pt/siterper/numeros/RPER50/ 50.4.pdf

Sanz, S., Zhelyazkova, D. y Cervera, A. (2017). Turismo gastronómico en la provincia de Valencia: ¿cómo lo perciben los turistas?. En Universitat de València (Eds.), Paisaje, turismo e innovación: actas del I Congreso «Paisaje, turismo e innovación» (pp. 157168).

Torres, F., Romero, J. y Viteri, M. (2017, 2018). Diversidad gastronómica y su aporte a la identidad cultural. Revista de la SEECI, 44, 113. http://www.seeci.net/revista/index.php/seeci/article/view/470/pdf_222

Vázquez, U. J. (2016). Place branding. La gastronomía como valor de marca y factor de atracción turística: el caso de España. Universidad Pontificia de Comillas.

\section{Francisca Ramón Fernández}

Profesora titular de Derecho Civil en la Universitat Politècnica de València. Licenciada y doctora en Derecho por la Universitat de València. En la actualidad es profesora titular de Derecho Civil, adscrita a la Escuela Técnica Superior de Ingeniería del Diseño (ETSID), en la Universitat Politècnica de València. Sus líneas de investigación están relacionadas con el patrimonio cultural y el turismo, y con las tecnologías de la información y comunicación (TIC).

frarafer@urb.upv.es

ORCID: http://orcid.org/0000-0002-0936-8229 